\title{
Floor Map
}

\section{Okinawa Convention Center}

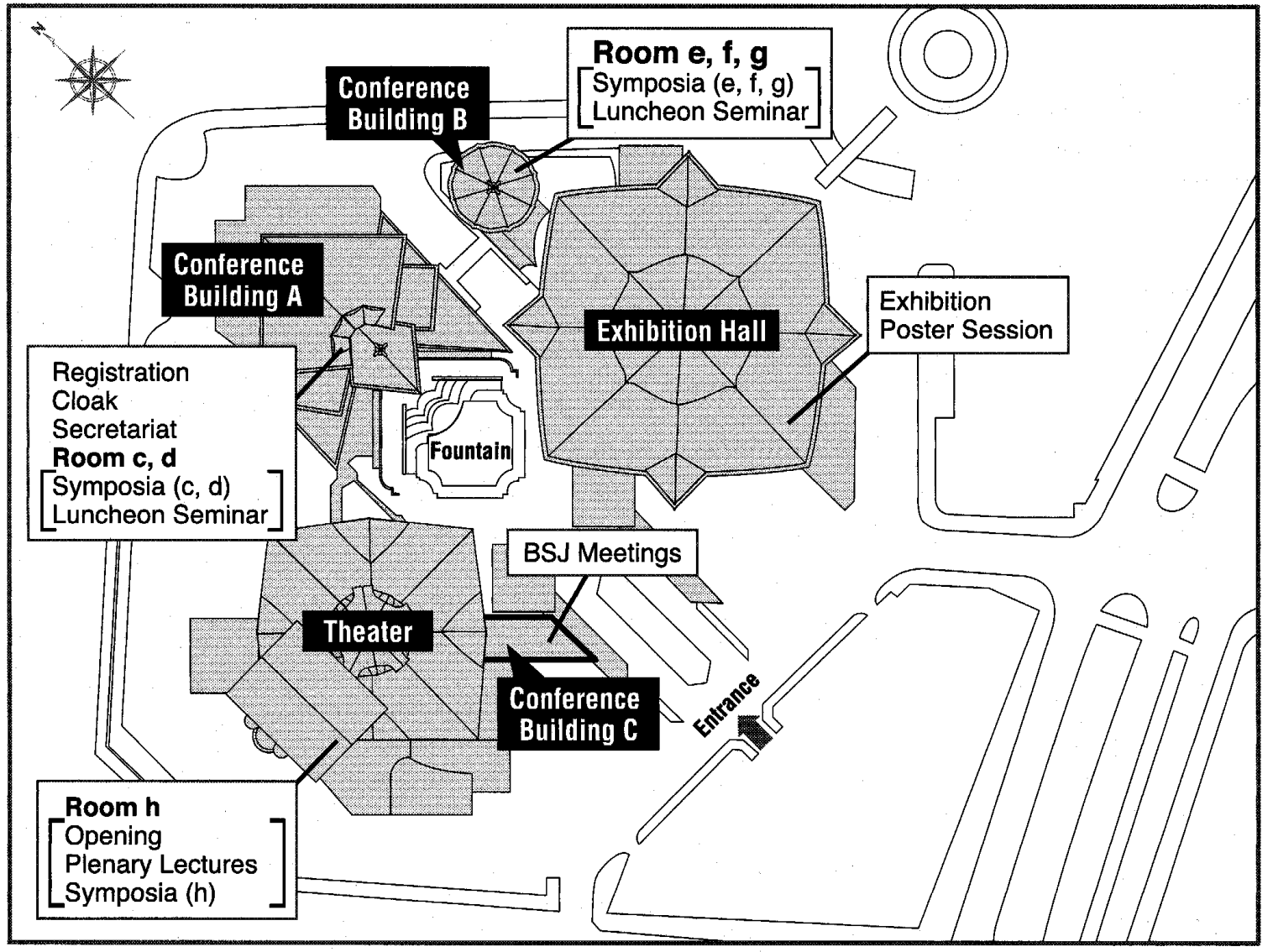

Conference Building A (1F)

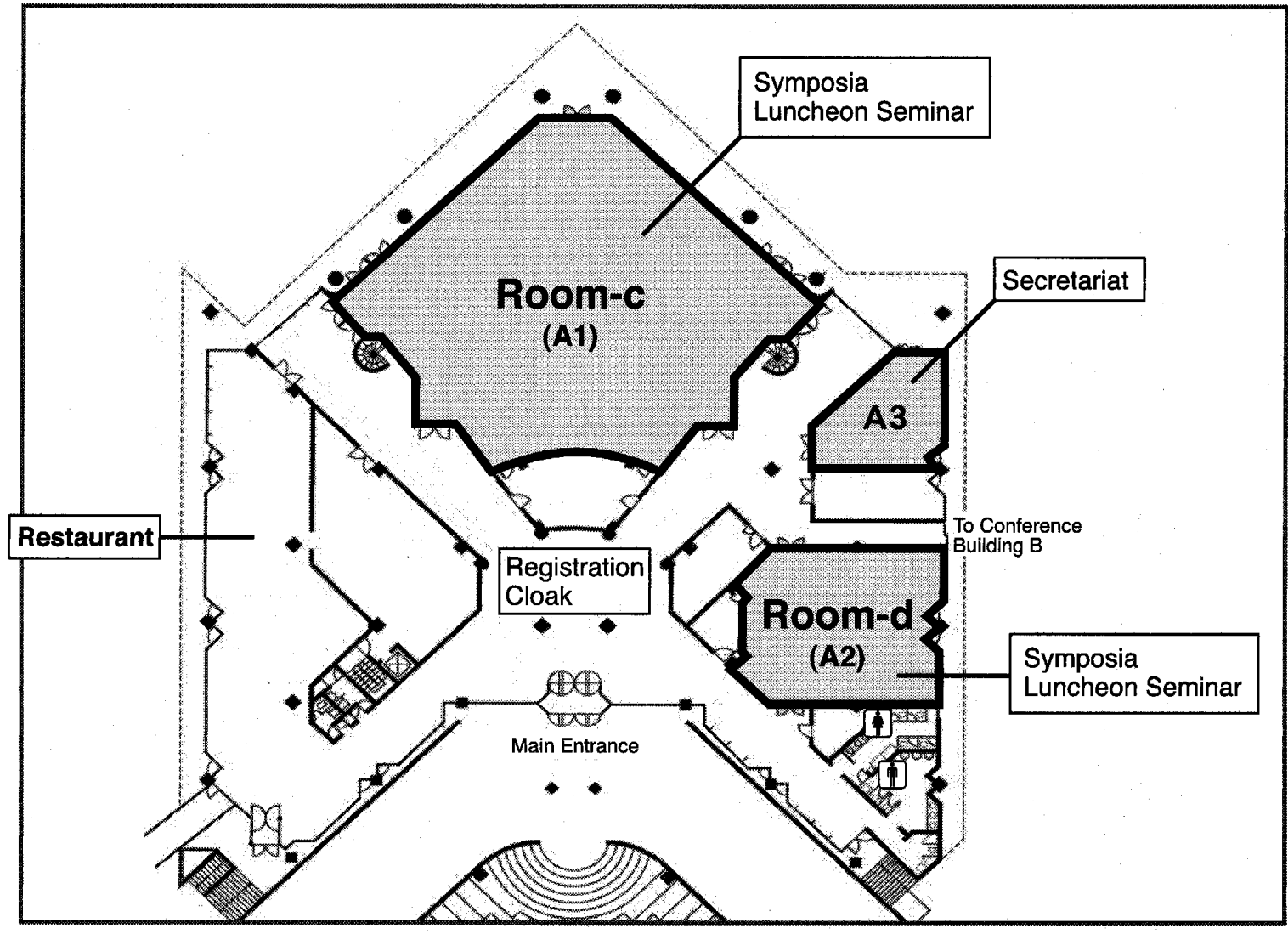




\section{Floor Map}

Conference Building B (2F)

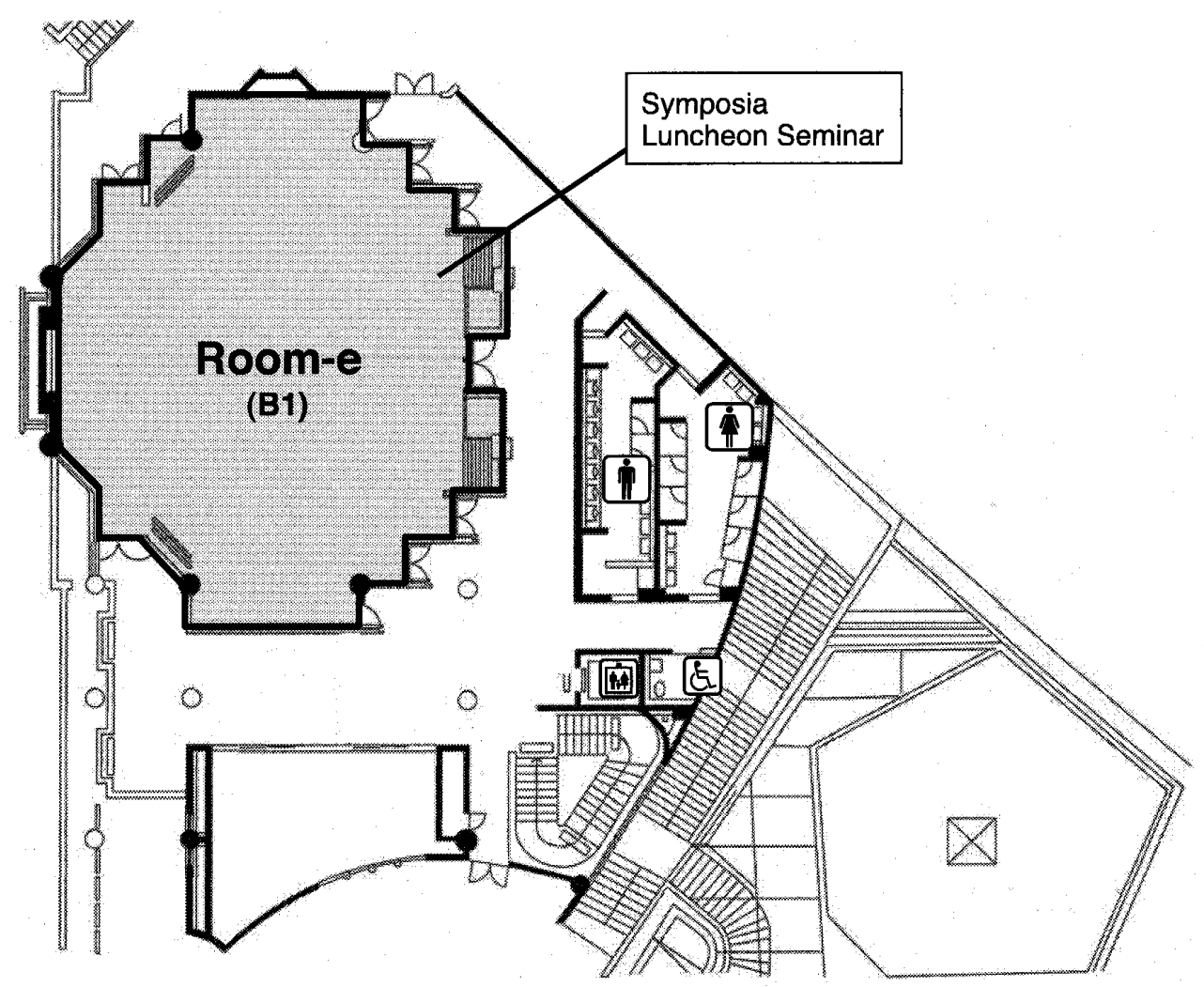

Conference Building B (1F)

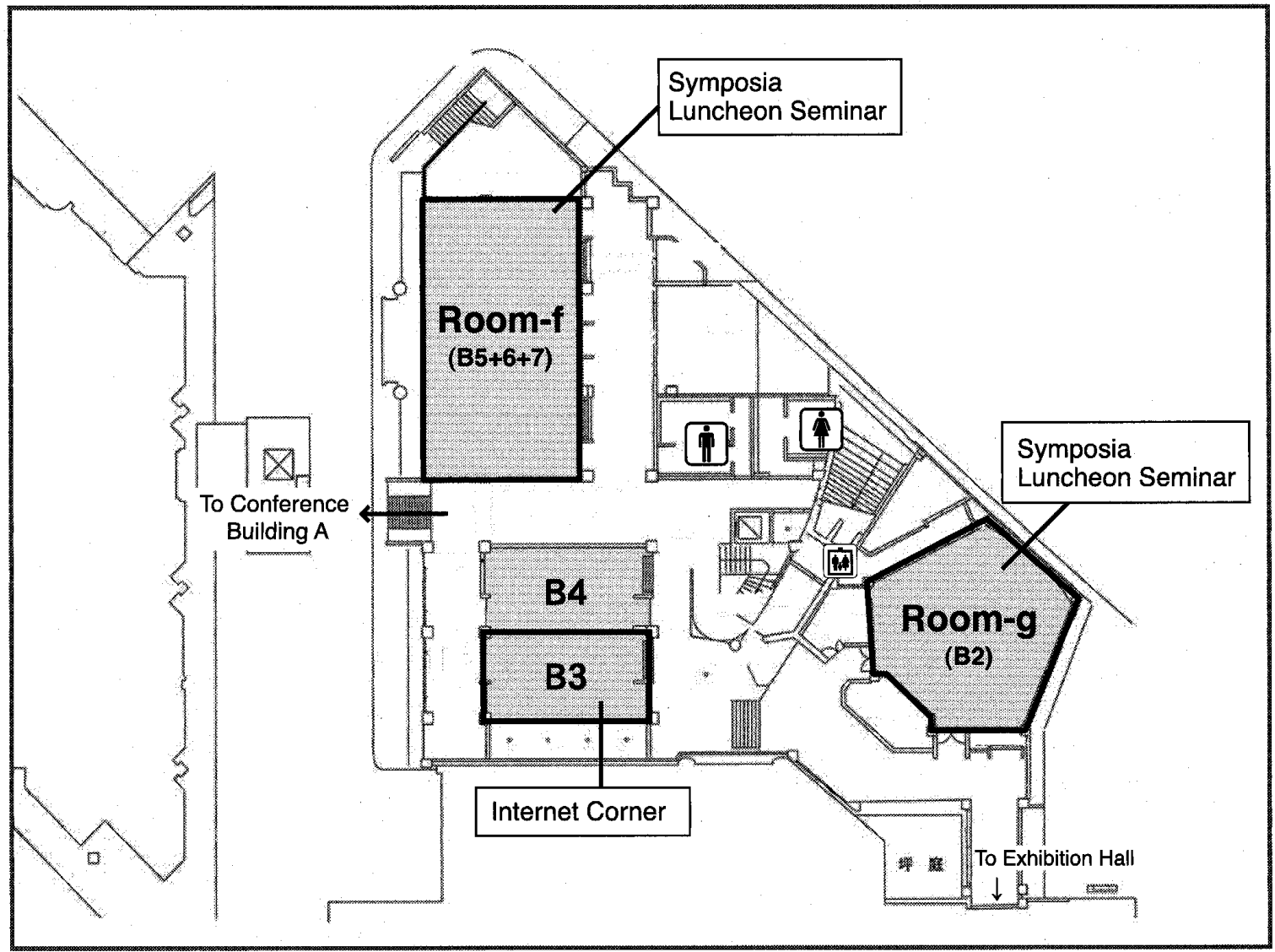




\section{Floor Map}

Theater / Conference Building C (1F)

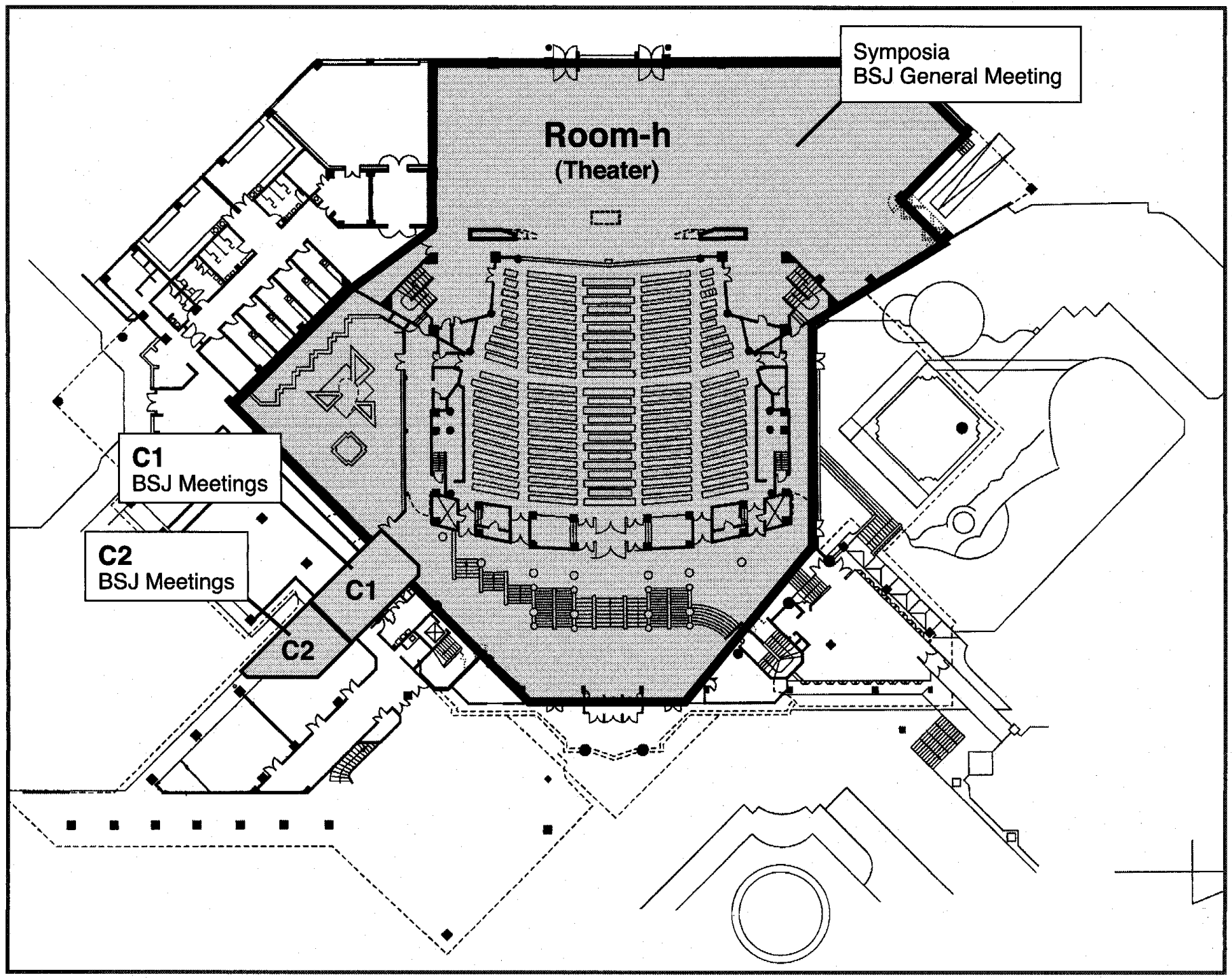




\section{Floor Map}

\section{Exhibition Hall}

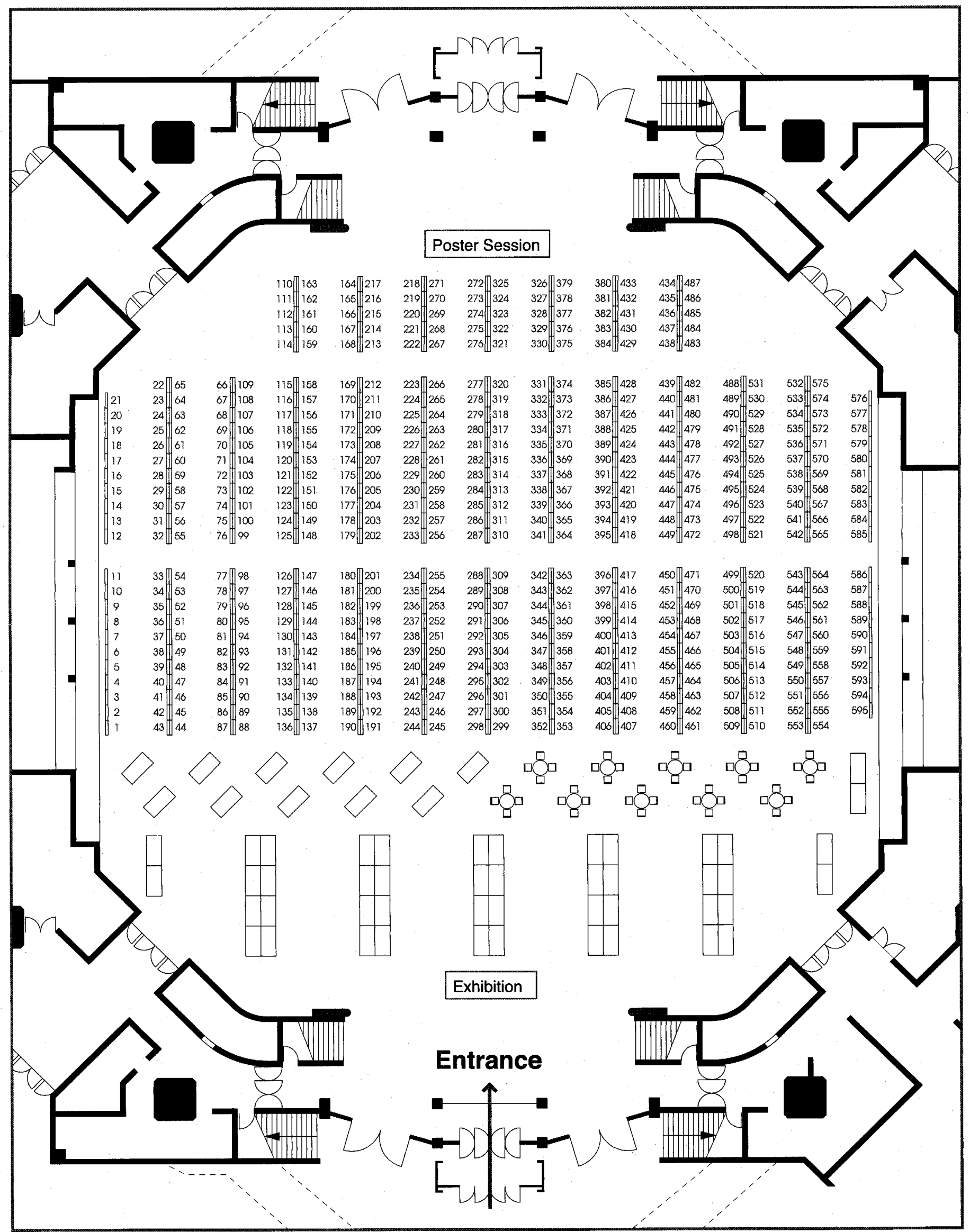

